\title{
Towards Sustainable Food System in Qatar: Household Food Waste and Consumption Behavior
}

\author{
Elmogiera Elawad $^{1, *}$, Mohamed Agied ${ }^{1}$, Mariam Althani ${ }^{1}$, Sana Abusin ${ }^{2}$ \\ ${ }^{1}$ Social \& Economic Survey Research Institute, Qatar University, Doha, Qatar \\ ${ }^{2}$ Sustainable environment consultant \\ *Corresponding author: elmogiera@qu.edu.qa
}

\begin{abstract}
It has been proofed that food wastage can be recognized at all level of food life cycle i.e. harvesting, manufacturing, distributing however, the largest contribution to food waste is the consumption stage by household. According to Parfitt et al, 2010; WRI, 2013 "household food waste" is define as the total losses that occur at the end of food lifecycle, which is final consumption, we consider the issue of waste of food as a deeply rooted issue of consumption behaviors, (Den 2008; Bowman 2007; Dogs 2002), and many commentators argue that domestic food waste is strongly influenced by consumer behaviors (Wharton, 2014). In the Arab countries, especially in the Gulf countries, high levels of food waste of recorded due to the social customs and traditions that control consumption patterns. Research efforts on the waste of food in the State of Qatar is very few and does not cover all Food waste, production and consumption chain, which start from production through delivery, storage, packaging, selling, and consumption. Through computer assisted telephone interview (CATI) with 1684 respondents This study covered the stage after purchase and consumption, aimed to understand the attitudes and behavior of individuals in Qatar towards food waste, and to identify types of food are often wasted and estimated the amount of waste as well. Survey respondents provided reason of food waste and Results indicate that people have an awareness regard food waste Furthermore; the study found out having more children was associated with reduced food waste perception and high-income households were strongly associated with increase in perception of food wastage as the income increases. Moreover, family give the persons a sense of responsibility towards food waste.
\end{abstract}

Keywords: environment, food waste, behavi

Cite This Article: Elmogiera Elawad, Mohamed Agied, Mariam Althani, and Sana Anusin, "Towards Sustainable Food System in Qatar: Household Food Waste and Consumption Behavior.” Journal of Food and Nutrition Research, vol. 6, no. 4 (2018): 200-204. doi: 10.12691/jfnr-6-4-1.

\section{Introduction}

Recently food waste is gaining more attention worldwide because of its direct effect on all aspect of life. For instance, food wastes result in money loss and increase price of goods resulting from increased demand. It also limits the chance of improving malnutrition situation of poorer who cannot afford buying good quality food. Environmentally food waste effect is even worse since the food decomposition is releasing methane; the most hazardous greenhouse gas that lead to global warming by 34 times compared with carbon dioxide. This underscore the importance of food recycling for sustainable use in other useful purposes such as natural fertilizer, and rreducing the amount of wasted food is a key element in developing a sustainable food system. [1].

It has been proofed that food wastage can be recognized at all level of food life cycle i.e. harvesting, manufacturing, distributing however, the largest contribution to food waste is the consumption stage by household. According to Parfitt et al., 2010, WRI, 2013 [2] "household food waste" is define as the total losses that occur at the end of food lifecycle which is final consumption.
Studying food-wasting behavior is very important since it increases households' awareness and encourages them to change their consumption behavior and attitude and hence contribute in sustainable development. The study comes as a motive by September 2015 of the Sustainable Development Goals, which called in goal 12 to "ensure sustainable consumption and production patterns."

Though behavior and culture are difficult to change, the ethical effect of wasting, huge amount of food while poverty is spreading worldwide in a very horrible way has to be consider by each household.

It has been mentioned by ecoMENA, 2016 that about half of the dumbed waste in landfills in Qatar is food based [3]. Qatar also had the highest consumption food rate and lowest recycling rate with food waste amount to 25 percent of all prepared food during Ramadan. According to the International Diabetes Federation, 23\% of adults in Qatar had diabetes in 2013, being third most affected country in the Middle East and North Africa.

There are differences in the various definitions applied to food waste. This is partly due to a lack of consensus [4]. In the basic form, 'food loss' and 'food waste' mean 'throwing uneaten food' away. The FAO defines food losses as a "change in the availability, edibility or quality of food that makes them unfit for human consumption" [5]. 
The aim of this paper is to identify determinants, the household perception of food, measurements of household food waste for this study include only waste that generated from homes (households), It concerns food and drink cooked or prepared at home but uneaten; Feed may be wasted at three points (strotmann, 2017) [6]:

1 - Between coming into the home and preparation,

2- Between preparation and serving, and

3- After serving (plate waste or leftovers).

In this study we add one more point, ppurchase stage some people have over estimate of their need as consumer, The food category that is considered in this study is the food and drink thrown away that was, at some point prior to disposal, edible (e.g. slice of bread, apples, meat), according to Household production theory Consumers choose foods for consumption within the context of their own and their household's preferences and available resources [1] (Becker,1965) [7], However in gulf countries consumers may overestimate their needs from goods and food (Suliman, 2000). [8]

The following section explained in details methods and survey of collected data section three presented results and finding of the study and discussion and section 4 concludes the paper.

\section{Study Objective}

The aim of this study is to identify determinants, the household perception of food waste, type of food waste usually wasted, cause of food waste according to respondents perspective, and test if there any perception different between respondents. The output of this study will help policy makers by providing policy options of how to reuse food waste in a sustainable way.

\section{Methodology}

The Qatar Semi-Annual Survey conducted by cellular phone in May 2017 to obtain a representative sample of respondents that included 744 Qataris, and 744 Whitecollar expatriates and 936 blue-collar expatriates. The distinction between White and Blue was determined by a cut-off of an income set at 4,000 QAR and over for White collar and under 4,000 QAR for Blue collar. This cut-off is based upon past research by SESRI showing this as a good predictor which aligns with income grouping, captured in SESRI's own face-to-face work as well as other demographic sources of information. The target population for the survey includes adults 18 years of age and older resident in Qatar. As the proportion of adult residents in Qatar (including both Qataris and expatriates) with a cellular phone is about 98 percent, a sample drawn from this type of frame is expected to have excellent coverage and representation of the target population. The phone numbers in the sample released for interviewing in batches to ensure that the complete call procedures followed for all numbers. The use of batches also improves the representativeness of the survey by balancing the distribution of phone numbers across respondent nationality and gender.
For every phone number in the sample, there are at least ten attempts to complete the interview. The phone calls made over different times during the day and different days of the week to maximize the changes of making contact with respondents. For phone numbers with breakoff and soft refusal, dedicated interviewers would try to contact and convert them to completed interviews.

The raw response rate (RR2, the ratio between the number of completes or partials and total sample sizes after excluding ineligibles and all unreached numbers assumed to be eligible) was $48.1 \%$.

\subsection{Questionnaire Development and Survey Administration}

With the numbers of completes and partials presented in table I-1, the maximum sampling error for a percentage is +/- 2.8 percentage points for the whole sample. The calculation of this sampling error takes into account the design effects (i.e., the effects from weighting and stratification). One possible interpretation of sampling errors is if the survey were conducted 100 times using the exact same procedure, the sampling errors would include the "true value" in 95 out of the 100 surveys. Note that the sampling errors can be calculated in this survey since the sample is based on a sampling scheme with known probabilities and that the sampling error for each specific question will vary.

The questions initially developed as omnibus questionnaire by researchers at SESRI. Questions initially written in English and then translated into Arabic and five other languages by professional translators. Researchers who are fluent in both English and Arabic carefully checked the translated version and modified the translation if necessary. Next, the questionnaires tested internally by SESRI. This allowed the project team to identify important concerns (such as comprehension) that affect quality of responses to the questions and the length of the interview.

During the data collection, 2,424 interviews completed in seven languages. The majority of these interviews were conducted in Arabic (51.8\%), followed by 27.1\% conducted in a South Asian language (Urdu, Hindi, Malayalam, Nepalese), $16.5 \%$ in English and the remaining interviews were conducted in Tagalog (4.6\%). Of the respondents, $70.4 \%$ were male and $29.6 \%$ were female. These percentages are prior to weighting the data to reflect actual population proportions. The survey administered in CATI mode. CATI is a computer assisted phone-based data collection method usually conducted by phoning the home or business of the respondent. In this study, cellular phones rather than landlines called by SESRI's call center.

\section{Result}

\subsection{Perceived Food Waste}

Descriptive analysis explored the demographic characteristics of the sample and perceptions of food waste. perceptions of food waste within family with 
respect to demographic variables were compared using the adjusted Wald test for samples with complex survey design the F-transformed version of the Pearson Chisquare statistic was used. Logistic regression was use to explore the association between perceptions of food waste within family and other demographic variables.

Table 1.

\begin{tabular}{|c|c|c|}
\hline & $\mathbf{N}$ & Percent\% (95\% CI) \\
\hline \multicolumn{3}{|l|}{ Perceived food waste within family } \\
\hline Yes & 415 & $25.1(22.4-28)$ \\
\hline No & 976 & 74.9(72-77.6) \\
\hline \multicolumn{3}{|l|}{ Perceived food waste in Qatar } \\
\hline Yes & 1,044 & $77.1(74.1-79.8)$ \\
\hline No & 295 & $22.9(20.2-25.9)$ \\
\hline \multicolumn{3}{|l|}{ Demographics } \\
\hline \multicolumn{3}{|l|}{ Gender } \\
\hline Male & 805 & $60.3(57-63.5)$ \\
\hline Female & 585 & $39.7(36.5-43)$ \\
\hline \multicolumn{3}{|l|}{ Nationality } \\
\hline Qatari & 736 & $25.1(23-27.4)$ \\
\hline Non-Qatari & 655 & 74.9(72.6-77) \\
\hline \multicolumn{3}{|l|}{ Marital status } \\
\hline Married & 1,006 & 79.3(76.9-81.6) \\
\hline Separated, divorced or widowed & 77 & $3.8(2.9-5.1)$ \\
\hline Never married & 304 & $16.8(14.8-19)$ \\
\hline \multicolumn{3}{|l|}{ Age group } \\
\hline Less than 24 & 283 & $7.2(6-8.5)$ \\
\hline $25-34$ & 824 & 37.1(34.4-40) \\
\hline $35-44$ & 635 & $30.8(28.1-33.5)$ \\
\hline $45-54$ & 363 & $17.2(15.1-19.5)$ \\
\hline 55 or more & 177 & 7.6(6.2-9.1) \\
\hline \multicolumn{3}{|l|}{ Number of children } \\
\hline Childless & 123 & $10.7(8.8-12.7)$ \\
\hline $1-3$ & 569 & 69.5(66.6-72.2) \\
\hline $4-6$ & 291 & $16.6(14.5-19)$ \\
\hline 7 or more & 91 & $3.2(2.4-4.2)$ \\
\hline \multicolumn{3}{|l|}{ Level of education } \\
\hline Less than Secondary school & 212 & 11.7(9.9-13.8) \\
\hline Secondary school & 358 & $18.9(16.6-21.4)$ \\
\hline Diploma & 129 & $10(8.2-12.3)$ \\
\hline University Graduate & 583 & $49.2(45.8-52.5)$ \\
\hline Master's Degree & 90 & $9.2(7.2-11.5)$ \\
\hline PH.D & 9 & $1(0.5-1.9)$ \\
\hline \multicolumn{3}{|l|}{ House hold Income } \\
\hline Less than 15000 & 345 & $50.1(46.5-53.8)$ \\
\hline $15000-25000$ & 149 & $20.6(17.6-24)$ \\
\hline $25000-50000$ & 295 & $12.4(10.8-14.1)$ \\
\hline $50000-70000$ & 151 & $6.6(5.5-7.9)$ \\
\hline More than 70000 & 230 & $10.3(8.8-11.9)$ \\
\hline
\end{tabular}

Characteristics of the sample shown in Table 1. Approximately, 3 out of every 4 perceived there is a food wastage problem in Qatar whereas 1 out of every 4 perceived it within their own family. The sample consisted of $60 \%$ males and $40 \%$ females, $25 \%$ were Qataris and $75 \%$ were non-Qataris. In the sample $79 \%$ were married, $17 \%$ never married and $4 \%$ separated, divorced or widowed. The average age was 39 and the sample had a median of two children where 1 out of 10 had no children, 7 out of 10 had 1-3 children and 2 out of 10 had four or more children. Half of the sample were university graduates and $10 \%$ had master's degree or higher. Half had a household income of 15,000 or less $20 \% 15,000$ 25,000 and $30 \%$ more than 25,000 .

There was no statistically significant difference between genders in food waste perception within the family where $24 \%$ of males considered there was food wastage within the family compared to $27 \%$ of females (P-value=0.26). Of those with no children, 17\% perceived food wastage within the family compare to $25 \%$ who had 1-3 children, $22 \%$ with 4-6 children and $22 \%$ who had more than 7 children whoever the number of children was also not statistically significant with (P-value=0.41). Individual's education level also not statistically significant with $(\mathrm{P}$-value $=0.1$ ) where $18 \%$ perceived food wastage had less than secondary education, 29\% with secondary education, $15 \%$ with diploma, $27 \%$ with university degree, 28\% with a master's degree and $26 \%$ with PH.D. Age was borderline significant with (Pvale $=0.08$ ) where $36 \%$ perceived food wastage where younger than 24 , 23\% between 25-34, 23\% between 35-44 $28 \%$ between $45-54$ and $21 \%$ were older than 55 . Income was strongly associated with perceived food wastage within the family with (P-value<0.001) where 19\% perceived food wastage had an income of less than 15,000 $17 \%$ with income between $15,000-25,000,29 \%$ with income $25,000-50,000,42 \%$ with income of 50,000 70,000 and $49 \%$ perceived food wastage had an income of 70,000 or more. There was a significant association between marital status and food waste perception where $23 \%$ of married individuals perceived food wastage, $31 \%$ who were separated or divorced or widowed and 33\% of those never married perceived food wastage within the family (P-value=0.01).

The most common reason for wasting food shown in Table 2 was food going past the expiration date 36.5\% and second reason was food going bad $27 \%$. Of those that perceived food waste $41 \%$ thought it was after consumption, approximately $20 \%$ thought it was it was at purchasing or storing at home and 16\% during processing or cooking.

Table 2. Reason for wasting food

\begin{tabular}{|l|c|c|}
\hline Reasons & N & Percent \\
\hline Food past expiration date & 521 & 36.5 \\
\hline Bought more than needed & 95 & 7.2 \\
\hline Food gone bad & 305 & 27 \\
\hline Didn't like the taste & 39 & 4 \\
\hline Prepared too much food & 129 & 8.8 \\
\hline Other & 71 & 6.1 \\
\hline Don' waste food & 164 & 10.5 \\
\hline
\end{tabular}

According to the respondents statement data shows that there are four main stages of food waste at home, we found that 4 out of 10 respondents agreed that they wasted the food after eating (consumption), while 2 out of 10 said that they wasted food at purchase stage (over estimate of their need), other distribution of stages see Figure 1. 


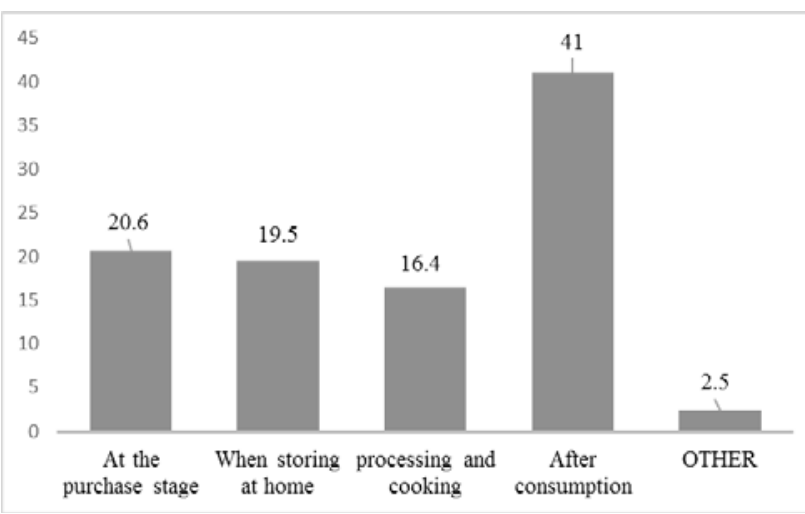

Figure 1. Stage of food wastage $\%$

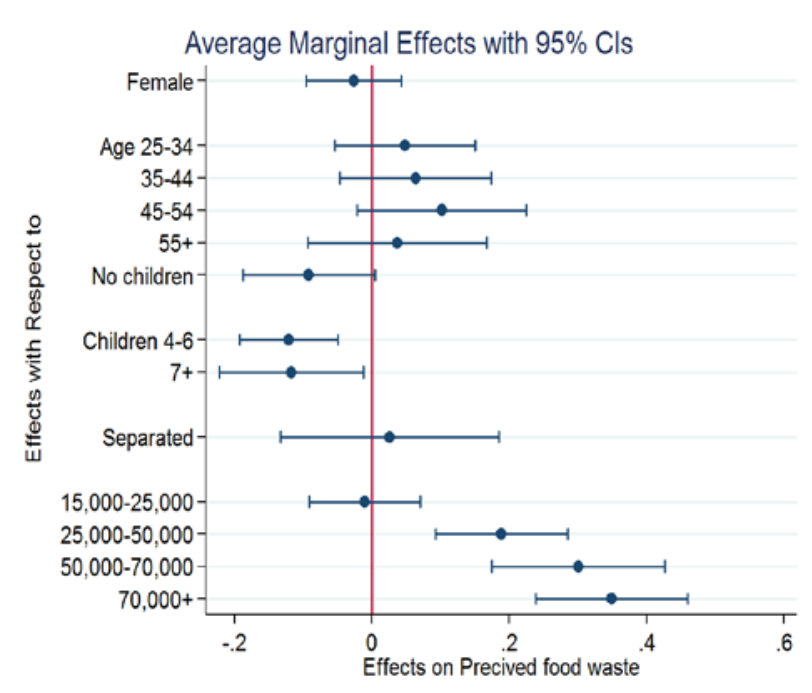

Figure 2. Average Marginal Effect

Table 3. Logistic regression analysis of perceived food waste and demographics

\begin{tabular}{|c|c|c|c|c|c|c|}
\hline & \multicolumn{3}{|c|}{\begin{tabular}{|l|} 
Model 1 \\
\end{tabular}} & \multicolumn{3}{|c|}{ Model 2* } \\
\hline & \begin{tabular}{|l} 
Odds \\
Ratio
\end{tabular} & $95 \%$ CI & \begin{tabular}{|l|} 
P- \\
value
\end{tabular} & $\begin{array}{l}\text { Odds } \\
\text { Ratio }\end{array}$ & $95 \% \mathrm{CI}$ & $\begin{array}{l}P- \\
\text { value }\end{array}$ \\
\hline \multicolumn{7}{|l|}{ Gender } \\
\hline Female & 0.84 & $0.54-1.32$ & 0.46 & 0.91 & $0.62-1.33$ & 0.63 \\
\hline \multicolumn{7}{|l|}{\begin{tabular}{|l|} 
Age \\
\end{tabular}} \\
\hline $25-34$ & 1.42 & $0.64-3.11$ & 0.39 & 1.06 & $0.63-1.78$ & 0.83 \\
\hline $35-44$ & 1.57 & $0.68-3.6$ & 0.29 & 1.12 & $0.60-2.06$ & 0.72 \\
\hline $45-54$ & 1.96 & $0.82-4.7$ & 0.13 & 1.62 & $0.8-3.26$ & 0.18 \\
\hline $55^{+}$ & 1.32 & $0.5-3.5$ & 0.58 & 0.95 & $0.43-2.1$ & 0.91 \\
\hline \multicolumn{7}{|c|}{ Number of children } \\
\hline None & 0.56 & $0.28-1.1$ & 0.09 & 0.66 & $0.32-1.36$ & 0.26 \\
\hline $4-6$ & \begin{tabular}{|l|}
0.44 \\
\end{tabular} & $0.26-0.74$ & 0.002 & 0.48 & $0.29-0.78$ & 0.003 \\
\hline $7+$ & 0.46 & $0.20-1.04$ & 0.06 & 0.5 & \begin{tabular}{|l|}
$0.23-1.09$ \\
\end{tabular} & 0.08 \\
\hline \multicolumn{7}{|c|}{\begin{tabular}{|l|} 
Marital status \\
\end{tabular}} \\
\hline Separated & 1.17 & $0.46-2.98$ & 0.74 & 1.17 & $0.48-2.82$ & 0.74 \\
\hline $\begin{array}{l}\text { Never } \\
\text { married }\end{array}$ & & & & 1.65 & $0.80-3.4$ & 0.17 \\
\hline \multicolumn{7}{|c|}{ Household Income } \\
\hline $\begin{array}{l}15000- \\
25000\end{array}$ & 0.93 & $0.49-1.73$ & 0.81 & 0.92 & $0.52-1.62$ & 0.77 \\
\hline $\begin{array}{l}25000- \\
50000\end{array}$ & 2.87 & $1.69-4.87$ & $<0.001$ & 2.26 & 1.43-3.57 & 0.001 \\
\hline $\begin{array}{l}50000- \\
70000\end{array}$ & 4.65 & $2.52-8.57$ & $<0.001$ & 3.79 & $2.27-6.33$ & $<0.001$ \\
\hline $\begin{array}{l}\text { More than } \\
70000\end{array}$ & 5.7 & 3.26-9.96 & $<0.001$ & 4.93 & 3.12-7.78 & $<0.001$ \\
\hline \multicolumn{7}{|c|}{$\begin{array}{l}\text { Model } 1 \text { excludes Never married group } \\
\text { Model } 2 \text { includes never married by assigning number of children }=0 \text { if } \\
\text { never married }\end{array}$} \\
\hline
\end{tabular}

Table 3 shows logistic regression of perceived food waste and covariates after adjustment for all demographic variables age and marital status were no longer significant, however having more children was significantly associated with reduced food waste perception and highincome households with income of 25,000 or more were strongly associated with increase in perception of food wastage as the income increases. Figure 1 and Figure 2 display marginal plots for the two models.

Table 4. Logistic regression analysis of perceived food waste and type of wasted food

\begin{tabular}{|l|c|c|c|}
\hline & Odds Ratio & 95\% CI & P-value \\
\hline Cereals or baked goods & 1.87 & $1.24-2.82$ & 0.003 \\
\hline Roots and tubers (potatoes) & 1.51 & $0.74-3.07$ & 0.26 \\
\hline Pulses and oilseeds & 2.2 & $1.05-4.6$ & 0.04 \\
\hline Fruits & 1.76 & $1.15-2.69$ & 0.009 \\
\hline Vegetables & 2.05 & $1.33-3.15$ & 0.001 \\
\hline Meat and meat products & 1.6 & $0.78-3.26$ & 0.2 \\
\hline Fish and seafood & 9 & $1.85-43.74$ & 0.006 \\
\hline Dairy and dairy products & 1.78 & $1.11-2.85$ & 0.02 \\
\hline Other & 0.57 & $0.37-0.88$ & 0.011 \\
\hline
\end{tabular}

Table 4 shows the association between perceived food waste and type of food wasted. Logistic regression shows that those that perceived food waste believed that the foods they overbought and end up wasting the most were Cereals or baked goods, pulses or oilseed, fruits, vegetables, fish and dairy compared to those that did not perceived food wastage within their families. Figure 3 illustrates marginal plot.

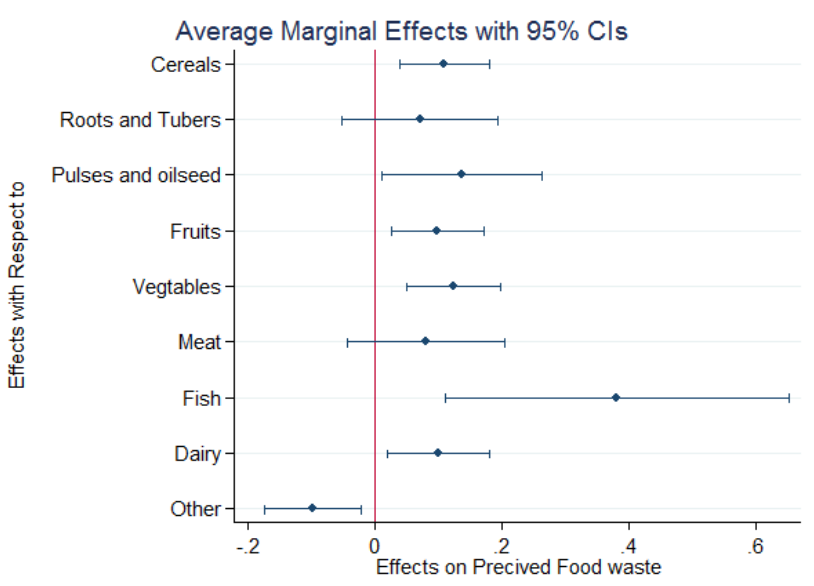

Figure 3. Average Marginal Effect-perceived food waste

\section{Conclusion}

Data shows that oonly $29.7 \%$ of all respondents agree that there is food waste problem at their household level, while that three quarter of respondent (75\%) agree with the exist of the problem in Qatar, this result is consistent with the social desirable, where Social desirability bias refers to the tendency of research subjects to give socially desirable responses instead of choosing responses that are reflective of their true feelings, the bias in responses due to this personality trait becomes a major issue when the scope of the study involves socially sensitive issues such 
as politics, religion, and environment or personal issues (Grimm, 2010) [9].

Data shows that there are four main causes for food waste at home, include bought more than needed and prepare more food, changing consumption habits requires persistent educational and public awareness efforts. This would include a combination of government policies and business strategies.

Data shows there is no statistically significant difference between genders in food waste perception within the family and also age is no statistically significant, however, there was a significant association between marital status and food waste perception, it have been approved that Social responsibility values decreased in young ages (Lake, 2016) [10] according to this study family give the persons a sense of responsibility towards food waste.

The study found out having more children was associated with reduced food waste perception and high-income households were strongly associated with increase in perception of food wastage as the income increases.

Data shows also, there are four main stage of food waste at home after consumption, at the purchase stage, when storing at home, processing and cooking.

Many considerations related to pollution, water scarcity, energy, waste, food insecurity and climate change materialize. Not surprisingly, most of these issues are human induced; human activity and unsustainable development practices have been some of the strongest driving forces behind the degradation of the finite world we live in [11].

To change behavior we need not only low but also we have to encourage individual and societal actions and the involvement of civil society and Academia, together with the media. Individuals need to change their consumption habits and lifestyles towards more sustainable behavior. (Arab environment sustainable consumption 2011).

We need to going forward, improved strategies for tackling consumption waste will need to be a priority for research and innovation for the global community dedicated to reducing food loss and waste. (WRI, 2013) [12].

\section{References}

[1] Francesco Marangon Tiziano Tempesta, Stefania Troiano,Daniel Vecchia, 2014, consumer attitudes and behaviour. to Food waste A study in the North -Eastern part of Italy, Rivista di Economia Agraria, Anno LXIX, n. 2-3, 2014: 201-209.

[2] Parfitt J., Barthel M., Macnaughton S. (2010). Food waste within food supply chains: quantification and potential for change to 2050. Philosophical Transactions of the Royal Society B: Biological Sciences, 365(1554): 3065-3081.

[3] Sybrandus Adema | March 9, 2016 | Conservation,food waste woes in Qatar, Food Middle East, Waste Management, www.ecomena.org/food-waste.

[4] Lebersorger, S., and Schneider, F. (2011). Discussion on the methodology for determining, food waste in household waste composition studies. Waste Management 31.1924-1933.

[5] HLPE, 2014. Food losses and waste in the context of sustainable food systems. A report by the High Level Panel of Experts on Food Security and Nutrition of the Committee on World Food Security.

[6] Christina Strotmann, Silke Friedrich, Judith Kreyenschmidt ,Petra Teitscheid and Guido Ritter, Comparing Food Provided and Wasted before and after Implementing Measures against Food Waste in Three Healthcare Food Service Facilities Sustainability 2017, 9, 1409.

[7] Becker GS. A theory of the allocation of time. Economic Journal. 1965; 75(299): 493-517.

[8] Ahmed Ali Sulaiman, The behavior of the consumer between theory and practice with a focus on the Saudi market. The book was published in $1421 \mathrm{AH} / 2000$ and the publisher is the Institute of Public Administration in Riyadh.

[9] Pamela Grimm, Social Desirability Bias, 2010. Wiem 02057 book: Wiley International Encyclopedia of Marketing.

[10] Wray-Lake, L., Syvertsen, A. K., \& Flanagan, C. A. (2016) Developmental change in social responsibility during adolescence: An ecological perspective. Developmental Psychology, 52(1), 130-142.

[11] United Nations Environment Program, Regional Office for West Asia (UNEP/ROWA), Sustainable Consumption and Production in the Arab Region, Arab Sustainable Development Report, 2015.

[12] Brian lipinski, craig hanson, james lomax, lisa kitinoja, richard waite and tim searchinger; Installment 2 of "Creating a Sustainable Food Future”, Reducing Food Loss and Waste, working paper, world resources institute WRI, 2013. 